\title{
Bone and joint changes in pneumatic drillers
}

\author{
M. J. BURKE,* E. C. FEAR, AND V. WRIGHT \\ From the Rheumatism Research Unit, University Department of Medicine, General Infirmary at Leeds
}

SUMMARY A clinical and radiological survey of 34 men who were pneumatic drillers employed by the North East Gas Board, was carried out to determine the prevalence of osteoarthrosis. Mild osteoarthrosis of the elbows was found in 2 subjects only. Two drillers had radiological evidence of

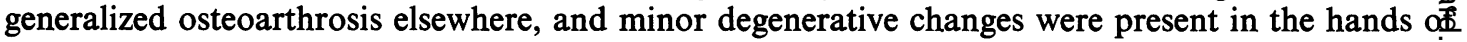
15 cases. Our findings do not support the view that pneumatic drillers are particularly prone tis develop osteoarthrosis.

The concept that primary osteoarthrosis represents a 'wear and tear' process in the joints has recently been revived. Radin et al. (1973) postulated that repetitive impulse loading on joints leads to degenerative changes. As one piece of evidence they suggested that users of pneumatic drills are prone to develop osteoarthrosis in the elbows and shoulders, as these joints absorb pounding when drilling, while their fingers and wrists, which are only vibrated, are unaffected.

We report here the results of a survey carried out to determine the prevalence of osteoarthrosis in a group of pneumatic drillers.

\section{Method}

Thirty-four unselected pneumatic drillers employed as 'road-pickers' by the North-East Gas Board in Leeds and Hull took part in the survey. All were men! The mean age was 39.9 years (range 22-58 years) and the mean duration of employment as drillers was 10.3 years (range 1-25 years). A full clinical examination was made with particular reference to the length of employment as a driller and type of instrument used. Inquiries were made into the presence of rheumatic symptoms, history suggestive of Raynaud's phenomenon, previous injuries, and family history of rheumatic disease. In the examination a detailed evaluation was made of the hands, elbows, shoulders, and cervical spine for swelling, tenderness, limitation of movement, and deformity. $X$-rays were taken of the hands, elbows, and shoulders, and a lateral view of the cervical spine

Accepted for publication August 20, 1976

* Present address: University Hospital of South Manchester. Correspondence to Prof. V. Wright, Rheumatism Research Unit, 36 Clarendon Road, Leeds LS2 9PJ was also obtained. The $x$-rays were graded for osteoarthrosis using standard criteria (Council for International Organisations of Medical Sciences: 1963) by two observers (M.J.B. and V.W.). The presence of cysts, spurs, and calcification was noted

\section{Results}

Fifteen of the 34 subjects had symptoms. 2, age 45 and 54, had Raynaud's phenomenon. 4 gave history of elbow pain, which was mild in 2. The other 2 had recently received treatment for tennis elbow. 8 had mild stiffness or cramp in the fingers? 2 complained of shoulder pain, of whom one had recently had a 'frozen shoulder'.

Excepting the 2 subjects with Raynaud's phenom enon, there was no correlation of symptoms wit age. Physical findings were unremarkable save fó the two with signs of tennis elbow.

\section{Radiology}

Evidence of mild osteoarthrosis in the hands was present in 17 subjects, confined in the majority to one or two joints. In 2 others, aged 55 and 58, more generalized osteoarthrosis was present. In one of these the brunt of the degenerative changes hatp fallen on the metacarpophalangeal joints. One्ड subject had mild bilateral osteoarthrosis affecting the radiocarpal joints. 5 had signs of old fractures the phalanges.

Radiological changes of mild osteoarthrosis were present in two elbow joints. One man aged 34 years had an osteophyte from the lower border of the lef radial head. He showed marked spurring at the triceps insertion and calcification alongside the lefit medial epicondyle. A second man aged 38 years 
showed spurring of the olecranon notch on the left and possibly on the right. At the triceps insertion spurring was moderate on the right and mild on the left. A third man aged 36 years had a moderate osteophyte arising from the olecranon notch on the right and a mild osteophyte in the same position on the left. There was no joint space narrowing or other evidence of osteoarthrosis. 'Spurring' of the olecranon at the triceps of insertion was found in 9 subjects (Fig. $a, b$ ). One other patient had a suggestion of calcification alongside the right radiohumeral joint.

Bone cysts were present in 8 subjects whose mean age was 46 years. In 6 they were found in the phalanges, in 4 in the lower ulna, in 2 in the capitate bone, and one each in the lunate and scaphoid. The presence of cysts correlated with age but not with symptoms.

$X$-rays of the shoulder showed sclerosis of the greater tuberosity in 6 cases. Degenerative changes in the cervical spine were present in 7 subjects whose mean age was 45 years. The changes were mainly at C5/6 and C6/7. They were mild in 5 and severe in 2 .

\section{Discussion}

Arthritis occurring as a result of using pneumatic tools was first described by Holtzmann (1929). He reported it in miners, hewers, metal workers, and riveters. In 8 of 10 of his cases the right elbow was affected with pain and limitation of movement. Rostock (1936), in a study of 744 miners using pneumatic boring tools, found arthritis of the elbow in 244 , of the shoulder in 3 , and of the wrist in 42 cases. However, these results were not compared with miners not using pneumatic tools.

In a study of occupational factors in rheumatism among coal miners (Lawrence, 1955) there was no statistical difference in the prevalence of osteoarthrosis of the elbow between those using pneumatic tools and those not. In a survey of the clinical effects of pneumatic tools in 286 workers, Hunter et al. (1945) found a low frequency of osteoarthrosis and recorded the changes as 'slight', although their diagnostic criteria were not discussed. 9 cases of arthritis were found among 78 riveters ( 7 elbow and 2 wrist), 9 out of 38 caulkers (all but one involving the elbow joint), 4 of 108 fettlers ( 3 elbow, 1 wrist), 8 of 37 holders-up ( 6 elbow, 2 wrist). The number of cases was too small, as Hunter et al. themselves report, to be of statistical significance and there is no convincing evidence that the arthritis was brought about by the use of pneumatic tools. This paper has been frequently misinterpreted in subsequent reviews of the pathogenesis of osteoarthrosis. 'There are clearly activity related specific joint degenerations;

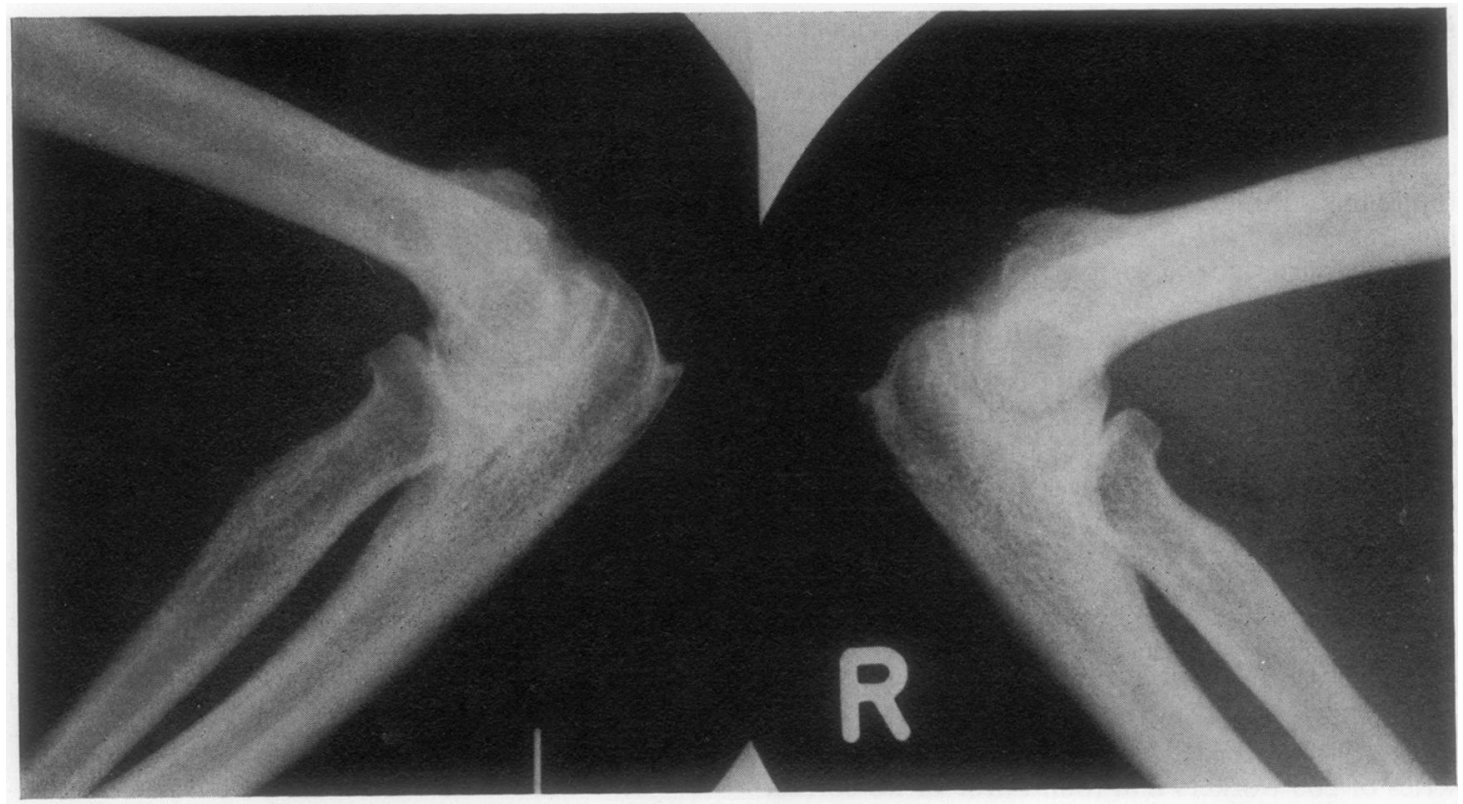

(a)

Fig. (a), (b) Spurring of the olecranon processes in pneumatic drillers. 


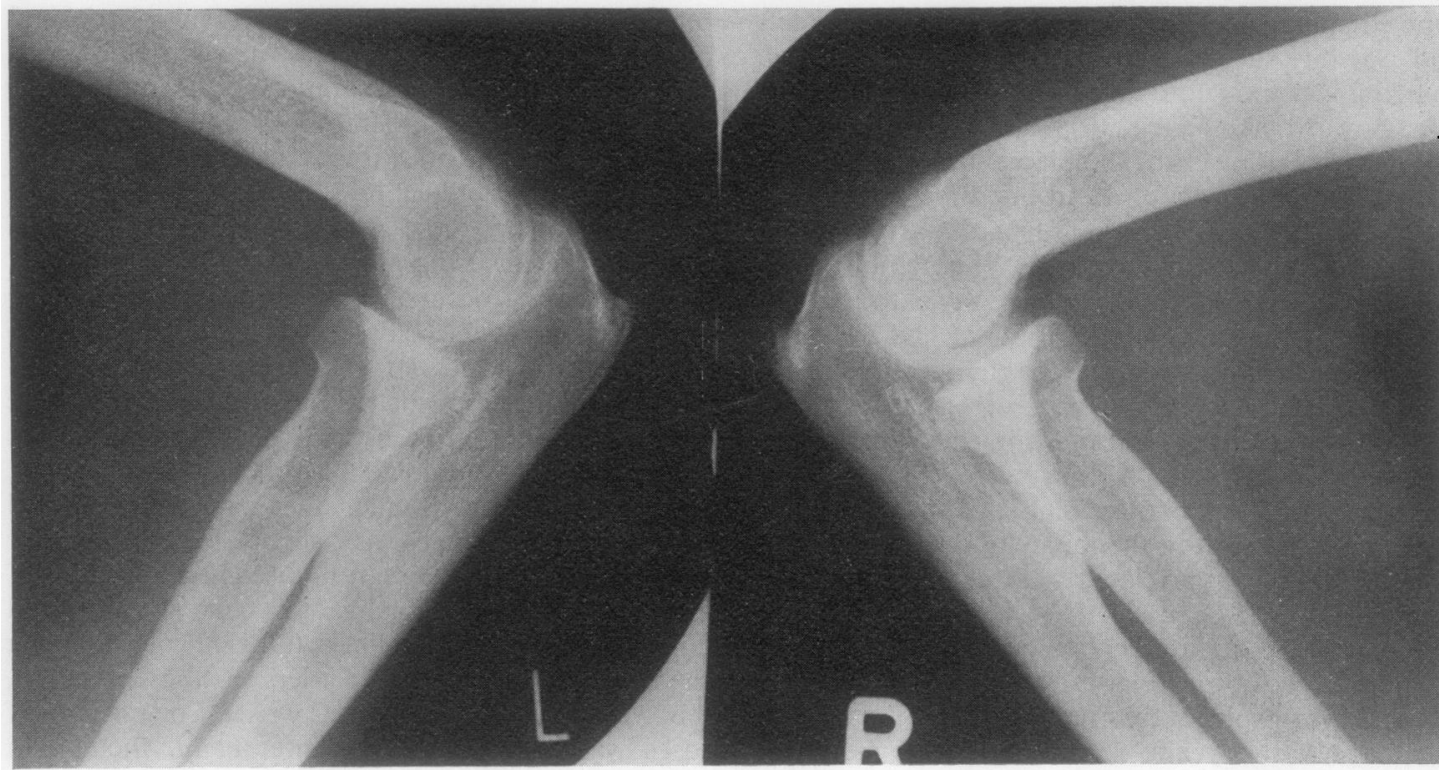

(b)

pneumatic drill operators get arthritis of elbows and shoulders, but not of fingers and wrists' (Radin et al., 1972). This conclusion clearly cannot be drawn from Hunter's paper.

In our survey of 34 pneumatic drillers radiological evidence of mild osteoarthrosis at the elbow was found in 2 subjects only, which is in keeping with the low frequency in Hunter's series.

Mechanical fatigue is a tempting hypothesis to explain the aetiology of osteoarthrosis and there is evidence to support the view (Radin et al., 1972; Freeman, 1973). The present study, however, provides no such confirmation. Indeed, parallel studies from our group suggest that impact, without injury or preceding abnormality of either joint contour or ligaments, is unlikely to produce osteoarthrosis (Adams, 1973).

Eight subjects of our series had radiological evidence of bone cysts. Such cysts in pneumatic drillers were first described by Brailsford (1936). Subsequently, McLaren (1937) found cysts in 20 workers of a series of 31 pneumatic drillers. Hunter et al. (1945) recorded bone cysts in $51.5 \%$ of their series of $\mathbf{2 8 6}$ workers and found little or no correlation of the cysts with the age of the workers or the length of time they had been engaged in handling pneumatic tools. They had observed similar cysts in men engaged in varying occupations who had neve? used pneumatic tools. In a recent review Taylor an $\Phi$ Palmerar (1975) found no significant difference in the number of bone cysts between those exposed tô vibration and controls.

Nine of our series of 34 drillers had spurring of thæ olecranon at the triceps insertion. Such spurring was described by Rostock (1936) who found an increase prevalence of the changes in miners using pneumatio tools compared with controls. In a series of 84 miners using pneumatic tools Barsi and Rossare (1963) found olecranon spurring in 21 cases.

\section{References}

Adams, I. D. (1973). Osteoarthrosis of the knee joint if sportsmen. MD thesis, University of Leeds.

Barsi, C., and Rossaro, R. (1963). Osteoartopatie de vibrazioni. Rassegna di Medicina Industriale e di Igriene do Lavaro, 32, 592-599.

Brailsford, J. F. (1936). Pathological changes in bones an $\mathbb{P}_{\text {. }}$ joints induced by injury. British Medical Journal, $\mathbf{2}$ 657-663.

Council for International Organisations of Medical Sciences (1963). Atlas of Standard Radiographs of Arthritis. Epidemig ology of Chronic Rheumatism, Vol. 2, Blackwell, Oxford Freeman, M. A. R. (1973). Adult Articular Cartilage. Pitman? London. 
Holtzmann, F. (1929). Erkrankungen durch Arbeiten mit Pressluftwerkzeugen. Zentralblatt für Gewerbehygiene und Unfallverhütung, 50, 1002-1003.

Hunter, D., McLaughlin, A. I. G., and Perry, K. M. A. (1945). Clinical effects of the use of pneumatic tools. British Journal of Industrial Medicine, 2, 10-16.

Lawrence, J. S. (1955). Rheumatism in coal miners. British Journal of Industrial Medicine, 12, 249-261.

McLaren, J. W. (1937). Disability of workers using pneumatic tools. Lancet, 2, 1296-1299.

Radin, E. L., Paul, I. L., and Rose, R. M. (1972). Role of mechanical factors in pathogenesis of primary osteo- arthrosis. Lancet, 1, 519-521.

Radin, E. L., Parker, G. H., Pugh, J. W., Steinberg, R. S., Paul, I. L., and Rose, R. M. (1973). Response of joints to impact loading. III. Relationship between trabecular microfracture and cartilage degeneration. Journal of Biomechanics, 6, 51.

Rostock, P. (1936). Gelenkschaden durch Arbeiten mit Presluftwerkzeugen und andere schwere Rörperliche Arbeit. Medizinische Klinik, 11, 341-343.

Taylor, W., and Palmerar, P. L. (1975). Vibration White Finger in Industry. Academic Press, London and New York. 